maining patient haemoglobin was $13.7 \mathrm{~g} \mathrm{dl}$ on presentation, blast count $160 \times 10^{9} 1$, and platelet count $18 \times 10^{9} / 1$. He had a cerebral haemorrhage with intravascular leukostasis.

\section{Discussion}

A previous necropsy study ${ }^{-}$of patients dying with high blast cell counts showed that leukaemic thrombi and aggregates were most commonly found in the lungs and brain and were unusual in patients with blast counts below $100 \quad 10 \% / 1$. Often patients became confused and dyspnoeic shortly before death. Nevertheless, unless postmortem examinations are performed, cerebral haemorrhage due to leukostasis is difficult to distinguish from that due to low platelet counts. The results of the fourth and fifth MRC trials showed that patients with high blast counts have a greatly increased early mortality, which cannot be accounted for by other high-risk factors. In the few patients on whom necropsy was performed leucocyte aggregates were found in the areas seen clinically to be affected. The cause of these aggregates is not clear, but the viscosity of whole blood with high blast counts is $75^{\circ}$ " greater than expected from the packed cell volume (PCV)." The viscosity of leukaemic-cell suspensions is only slightly greater than that of red cells of the same PCV. Leukaemic cells are much less deformable than red blood cells, "and the pressure required to force nondeformable cells through filters increases with increasing PCV." Most patients with leukaemia and a high blast count have a low haemoglobin concentration on presentation, and thus the actual viscosity is no greater than that of a normal PCV of $0.47\left(47^{\circ}{ }_{1}\right)$. In the patients who died within a week, however, the haemoglobin concentration was significantly higher than in the survivors. Since viscosity is log-linearly related to $\mathrm{PCV}$ throughout the range of PCV these patients would have had a higher wholeblood viscosity. Thomas et al " showed that a small change in PCV in the normal range could produce a $50^{\prime \prime}$ " change in cerebral blood flow. The combination of a viscosity greater than expected for a given PCV together with rigid blast cells may have led to leukostasis. The three patients described deteriorated rapidly on transfusion to haemoglobin concentrations of at least $10 \mathrm{~g} / \mathrm{dl}$, and although necropsy was not carried out in case 3, leukostasis was the most likely explanation of the clinical events.
The platelet count in the reported cases fell over the 24 hours after admission. This was unlikely to have been due to chemotherapy, and there was no bleeding from venepuncture sites or fresh haemorrhage such as may occur with disseminated intravascular coagulation, although blood cultures were positive in one patient. The fall in platelet count could have led to cerebral bleeding, but the postmortem examinations showed leukostasis as described by Freireich et al. ${ }^{*}$ Alternatively, the fall could have been produced by haemorrhage associated with leukostasis consuming platelets. In either case it would have predisposed to further bleeding in areas of leukostasis.

As patients with high blast counts whose disease went into remission survived as long as those with lower counts, ${ }^{1}$ it is important to prevent these early deaths. A haemoglobin concentration above $10 \mathrm{~g} / \mathrm{dl}$ is an adverse risk factor. Transfusing patients to this concentration before their blast count has been reduced should be avoided as it may lead to early death by encouraging leukostasis. The only survivors whose haemoglobin concentration was over $10 \mathrm{~g} / \mathrm{dl}$ had received chemotherapy on the day of diagnosis. Conventional chemotherapy halved the blast count within 24 hours in most patients and should be started as a matter of urgency.

I thank Professor D A G Galton for his help and tor giving me access to the reporting forms of the MRC's fourth and fifth trials, and Dr J Piris and Dr T M Parry, of the department of pathology, for the figure.

\section{References}

1 Medical Research Council, British fournal of Haematology, 1974, 27, 373.

- Chang, H P, et al, Medicine, 1976, 55, 259.

${ }^{3}$ Smith, I E, et al, Cancer, 1977, 39, 1710.

4 Freireich, E J, et al, Cancer, 1960, 13, 146

Bodey, G P, et al, Cancer, 1966, 19, 781.

"Roberts, W C, Bodey, G P, and Wertlock, P T, American fournal of Cardiology, 1968, 21, 388.

' McKee, L C, jun, and Collins, R D, Medicine, 1974, 53, 463.

${ }^{*}$ Lichtman, M A, Fournal of Clinical Investigation, 1973, 52, 350.

${ }^{9}$ Seaman, G F, and Swank, R L, Federation Proceedings, 1964, 23, 111.

"Thomas, D J, et al, Lancet, 1977, 2, 941.

\title{
Reversal of clofibrate-induced cholesterol oversaturation of bile with chenodeoxycholic acid
}

\author{
M C BATESON, P E ROSS, J MURISON, IAN A D BOUCHIER
}

British Medical fournal, 1978, 1, 1171-1173

\section{Summary and conclusions}

Giving clofibrate $2 \mathrm{~g}$ daily to seven patients significantly increased the biliary cholesterol concentration while the proportion of bile acids fell. Five patients on established clofibrate treatment were given $750 \mathrm{mg}$ of chenodeoxy-

\footnotetext{
Department of Medicine, Ninewells Hospital and Medical School, Dundee DD1 9SY

M C BATESON, MB, MRCP, lecturer

P E ROSS, PHD, MSC, lecturer

J MURISON, LRIC, chief technician

IAN A D BOUCHIER, MD, FRCP, professor
}

cholic acid (CDCA) daily for one month. Biliary lipid analysis after the CDCA treatment showed a significant fall in the proportion of cholesterol and a rise in that of bile acids. The serum lipid concentrations, which had already been reduced by diet and clofibrate, showed a further significant reduction after the introduction of CDCA.

This study suggests that CDCA may be usefully combined with clofibrate to reverse the tendency towards cholesterol saturation of bile and enhance the effect of lowering serum lipid concentrations.

\section{Introduction}

Clofibrate is used extensively for hyperlipidaemia and is effective and palatable. It acts on the liver to enhance the biliary 
secretion of cholesterol ${ }^{1}$ and suppress the secretion of bile acids. ${ }^{12}$ Nevertheless, treatment with clofibrate leads to increased formation of cholesterol gall stones and clinically apparent gallstone disease. ${ }^{13-5}$ Because this might require surgical intervention the lithogenic potential of the drug is a serious limitation on its use. On the other hand, chenodeoxycholic acid (CDCA) reduces biliary cholesterol ${ }^{67}$ and has been used to dissolve cholesterol gall stones.

Our study was designed to assess whether the increase in biliary cholesterol induced by clofibrate was sustained, and, if so, whether it could be reversed by CDCA without any deterioration in the control of hyperlipidaemia.

\section{Patients and methods}

Seven patients (six men and one woman) aged 41-55 years with normal, functioning gall bladders who were not receiving drugs underwent duodenal drainage after intravenous administration of cholecystokinin with analysis of biliary lipids as described. ${ }^{\text {* Five had }}$ hypertriglyceridaemia (triglyceride concentration above $2.48 \mathrm{mmol} / 1$ $\left(200 \mathrm{mg} / 100 \mathrm{ml}^{*}\right)$ ), and two both hypertriglyceridaemia and hypercholesterolaemia (cholesterol concentration above $7.8 \mathrm{mmol} / 1$ (300 $\mathrm{mg} / 100 \mathrm{ml})$ ). All were maintained throughout the study on a low carbohydrate diet $(3 \cdot 4-7 \cdot 0 \mathrm{MJ} ; 812-1672 \mathrm{kcal})$, with no significant change in weight. The patients were given clofibrate $2 \mathrm{~g}$ daily for six to 18 months, after which duodenal drainage and biliary lipid analysis were again carried out.

Five patients (four men and one woman) aged 48-57 who had been receiving prolonged clofibrate treatment $(2 \mathrm{~g}$ daily $)$ underwent duodenal intubation and analysis of biliary lipid proportions. Treatment with $750 \mathrm{mg}$ of CDCA daily was then instituted in addition to the clofibrate. Biliary lipid analysis was repeated after one month. Three patients had mixed hyperlipidaemia, one hypercholesterolaemia, and one hypertriglyceridaemia. Three were taking a low carbohydrate $\operatorname{diet}(4 \cdot 2-4 \cdot 6 \mathrm{MJ} ; 1003-1098 \mathrm{kcal})$ and two a low animal-fat diet. Serum cholesterol and triglyceride concentrations were measured before and after CDCA treatment with Boehringer kit methods 15737 and 16644.

Differences in biliary lipid proportions were analysed with Student's paired $t$ test. A cholesterol saturation index was calculated from the data of Admirand and Small ${ }^{9}$ with use of Thomas and Hofmann's nomogram. ${ }^{10}$ Results are expressed as means $\pm \mathrm{SD}$.

*For conversion of serum triglyceride values from mass to substance concentrations we used a tripalmitin standard, giving the factor $100 \mathrm{mg} / 100 \mathrm{ml} \equiv$ $1.24 \mathrm{mmol} / 1$.

TABLE I-Mean $( \pm S D)$ results of biliary lipid analysis and cholesterol saturation index before and after clofibrate treatment in seven patients. Lipid proportions expressed as mol/100 $\mathrm{mol}$

\begin{tabular}{|c|c|c|c|c|}
\hline & Phospholipids & Bile acids & Cholesterol & Saturation index \\
\hline $\begin{array}{l}\text { Before } \\
\text { After } \\
\text { P }\end{array}$ & $\begin{array}{c}18.97 \pm 6.05 \\
28.64+12 \cdot 15 \\
<0.05\end{array}$ & $\begin{array}{c}69 \cdot 78+5 \cdot 02 \\
55 \cdot 21+12 \cdot 36 \\
<0.02\end{array}$ & $\begin{array}{c}11 \cdot 29 \pm 5.37 \\
16.24 \pm 3.47 \\
<0.05\end{array}$ & $\begin{array}{c}1.19+0.58 \\
1.98+0.48 \\
<0.05\end{array}$ \\
\hline
\end{tabular}

TABLE II-Mean $( \pm S D)$ results of biliary lipid analysis and cholesterol saturation index before and after treatment with CDCA 250-750 mg daily during established clofibrate treatment in five patients. Lipid proportions expressed as mol $100 \mathrm{~mol}$

\begin{tabular}{|c|c|c|c|c|}
\hline & Phospholipids & Bile acids & Cholesterol & Saturation index \\
\hline $\begin{array}{l}\text { Before } \\
\text { After } \\
\text { P }\end{array}$ & $\begin{array}{c}27.91+11 \cdot 26 \\
13.62 \pm 3.07 \\
<0.01\end{array}$ & $\begin{array}{c}54 \cdot 80 \pm 12 \cdot 72 \\
76 \cdot 29 \pm 3 \cdot 27 \\
<0 \cdot 01\end{array}$ & $\begin{array}{c}17 \cdot 29 \pm 7 \cdot 82 \\
10 \cdot 14 \pm 4.99 \\
<0.025\end{array}$ & $\begin{array}{c}2.09+0.93 \\
1.14+0.64 \\
<0.025\end{array}$ \\
\hline
\end{tabular}

\section{Results}

Bile samples from the seven patients with normal gall bladders were analysed before and after clofibrate treatment. There was a significant increase in the cholesterol and phospholipid proportions and a fall in the bile acid content of bile, with a consequent deterioration in the cholesterol-holding capacity of the bile (table I). After a year's treatment one patient developed radiolucent calculi, which were larger after a second year and persisted for a further year after the withdrawal of clofibrate.

Table II gives the results of biliary lipid analysis in the five patients $\overrightarrow{\overline{\bar{N}}}$ who had been receiving prolonged clofibrate treatment. The composi- $\bar{\sigma}$ tion of the bile was similar to that in the seven patients (table I) established on clofibrate at the beginning of the study. During CDCA $\overline{\bar{c}}$ treatment the bile acid and phospholipid proportions of the total $\overrightarrow{\mathbb{D}}$ lipids rose significantly in all five patients, and the cholesterol proportion and saturation index fell in four. In each patient there was a significant increase in CDCA in the bile acids (mean rise from $\overrightarrow{0}$ $50 \cdot 15 \pm 9 \cdot 28 \mathrm{~mol} / 100 \mathrm{~mol}$ to $85 \cdot 94 \pm 14.83 \mathrm{~mol} / 100 \mathrm{~mol} ; \mathrm{P}<0 \cdot 05)$, together with a fall in the proportions of cholic acid $(27.04 \pm 11.04 \mathrm{~mol} \overrightarrow{\mathrm{C}}$ to $7 \cdot 29 \pm 10.23 \mathrm{~mol} / 100 \mathrm{~mol} ; \mathrm{P}<0.01)$, deoxycholic acid $(18.38 \pm 6.25 \mathrm{~W}$ mol to $3.62 \pm 4.85 \mathrm{~mol} 100 \mathrm{~mol} ; \mathrm{P}<0.025)$, and lithocholic acid $(3 \cdot 23 \pm 2 \cdot 41 \mathrm{~mol}$ to $2 \cdot 14 \pm 1.97 \mathrm{~mol} / 100 \mathrm{~mol} ; \mathrm{NS})$. Ursodeoxycholic acid was found in some bile samples but showed no trend to increase or decrease during treatment.

The serum lipid concentrations in the five patients fell after the diet and clofibrate treatment were introduced and decreased further when CDCA was added. The mean serum cholesterol concentration $\vec{V}$ fell with CDCA treatment from $6.82 \pm 1.06$ to $5.94 \pm 0.53 \mathrm{mmol} / \mathrm{l}$ $(263 \pm 41$ to $229 \pm 20 \mathrm{mg} / 100 \mathrm{ml})(\mathrm{P}<0.02)$, and there was also a reduction in the mean serum triglyceride concentration from $1.90 \pm \sigma$ 0.72 to $1.32 \pm 0.41 \mathrm{mmol} / 1(153 \pm 58$ to $106 \pm 33 \mathrm{mg} / 100 \mathrm{ml})(P<0.05)$. Both concentrations fell in each patient.

Three patients were studied serially before clofibrate treatment, $\overrightarrow{0}$ after clofibrate treatment for $12-18$ months, and after receiving clofibrate plus CDCA for one month. Table III gives the results in $\infty$ these patients, which confirm that the proportion of cholesterol in bile returned to a value similar to that found before any drug treatment was instituted.

\section{Discussion}

Our results show that the increase in cholesterol induced in $\frac{3}{3}$ bile by clofibrate persists for six months or more. Although bile is minimally oversaturated with cholesterol in many normal people, ${ }^{11} 1:$ clofibrate accentuates this, so that cholesterol oversaturation is more common and pronounced. Thus the composition of the fasting bile in our patients receiving clofibrate was similar to that in patients with gall-stone disease ${ }^{*}$ and different from that in patients with untreated hyperlipidaemia. ${ }^{13}$ The increase in cholesterol and the deterioration in the ability of bile to hold cholesterol in solution was reversed when CDCA 윽 was given in addition. Since cholesterol saturation of bile is $N$ thought to be the crucial factor in the aetiology of gall stones, $D$ we suggest that combining the two drugs might protect against cholelithiasis.

Interestingly, the concentration of serum lipids also fell after CDCA was added to clofibrate treatment. CDCA alone decreases $\omega$ high serum triglyceride concentrations ${ }^{14}{ }^{15}$ but has not been found so far to affect serum cholesterol concentrations. A combination of the two drugs might be useful in managing hyperlipidaemia, especially hypertriglyceridaemia, and might + permit a reduction in the dose of each agent without loss of control. It is unlikely that factors other than drug treatment $\vec{D}$ appreciably affected our results. During the study there was no $\frac{\rho}{\mathbb{Q}}$ TABLE III-Results of biliary lipid analysis and cholesterol saturation index in three patients before treatment, while taking clofibrate, and while taking clofibrate and $\underset{0}{0}$
CDCA. Lipid proportions expressed as mol/100 mol

\begin{tabular}{|c|c|c|c|c|c|}
\hline & & Phospholipids & Bile acids & Cholesterol & Saturation index \\
\hline $\begin{array}{l}\text { Before treatment } \\
\text { After clofibrate } \\
\text { After clofibrate and CDCA }\end{array}$ & $\begin{array}{ll}\cdots & \cdots \\
\cdots & \cdots \\
\cdots & \cdots\end{array}$ & $\begin{array}{c}6 \cdot 21 ; 10 \cdot 61 ; 23 \cdot 60 \\
23 \cdot 36 ; 38 \cdot 60 ; 38 \cdot 88 \\
13 \cdot 30 ; 14 \cdot 66 ; 16 \cdot 72\end{array}$ & $\begin{array}{l}67 \cdot 10 ; 75 \cdot 90 ; 84 \cdot 16 \\
42 \cdot 76 ; 45 \cdot 07 ; 72 \cdot 07 \\
75 \cdot 03 ; 79 \cdot 45 ; 80 \cdot 09\end{array}$ & $\begin{array}{c}5.42 ; 9.63 ; 13.50 \\
4.57 ; 16.06 ; 18.63 \\
5.24 ; 7.24 ; 8.25\end{array}$ & $\begin{array}{l}0.54 ; 1.34 ; 1.58 \\
0.46 ; 2.23 ; 2.72 \\
0.57 ; 0.81 ; 0.86\end{array}$ \\
\hline
\end{tabular}


change in either weight ${ }^{161 ;}$ or diet. ${ }^{1-19}$ All patients were studied under standard conditions after fasting for about 12 hours.

These preliminary findings suggest that CDCA is a potentially useful adjunct to clofibrate treatment. It remains to be seen whether the effect on serum lipids and bile is sustained. So far, CDCA has been free from appreciable toxic effects, although in some cases the dose has had to be reduced because of diarrhoea. Theoretical considerations suggesting hepatotoxicity have been disproved by clinical experience in dissolving gall stones.

Since CDCA reversed the deterioration in bile caused by clofibrate and improved serum lipid control it merits further study in the management of hyperlipidaemia.

This work was supported by a grant from Weddel Pharmaceuticals.

\author{
References \\ 1 Pertsemlidis, D, Panveiliwalla, D, and Ahrens, E H, Gastroenterology, \\ 1974, 66, 565
}

${ }^{2}$ Einarsson, K, Hellström, K, and Kallner, M, European fournal of Clinical Investigation, 1973, 3, 345.

${ }^{3}$ Coronary Drug Project Research Group, fournal of the American Medical Association, 1975, 231, 360.

4 Coronary Drug Project Research Group, New England fournal of Medicine, 1977, 296, 1185.

${ }^{5}$ Cooper, J, Geizerova, H, and Oliver, M H, Lancet, 1975, 1, 1083.

${ }^{6}$ Mok, H Y I, Bell, G D, and Dowling, R H, Lancet, 1974, 2, 253.

Thistle, J L, et al, American fournal of Digestive Diseases, 1977, 22, 1.

${ }^{8}$ Bateson, M C, et al, Gut, 1977, 18, 599.

${ }^{9}$ Admirand, W, and Small, D M, fournal of Clinical Investigation, 1968, 47, 1043.

10 Thomas, P T, and Hofmann, A F, Gastroenterology, 1973, 65, 698

${ }^{11}$ Holzbach, R T, et al, fournal of Clinical Investigation, 1973, 52, 1467.

${ }^{12}$ Hegardt, F G, and Dam, H, Zeitschrift für Ernährungswissenschaft, 1971, $10,223$.

${ }^{13}$ Bateson, M C, et al, Gut, 1976, 17, 814.

${ }_{14}$ Miller, N E, and Nestel, P J, Lancet, 1974, 2, 929.

15. Bateson, M C, et al, British fournal of Clinical Pharmacology, 1978, 5, 249.

${ }^{16}$ Miettinen, T A, Circulation, 1971, 44, 842.

${ }^{17}$ Bennion, L J, and Grundy, S M, Fournal of Clinical Investigation, 1975, 56, 996.

18 Watanabe, N, Gimbel, N S, and Johnston, C G, Archives of Surgery, $1962,85,136$

${ }^{19}$ Grundy, S M, fournal of Clinical Investigation, 1975, 55, 269

(Accepted 24 February 1978)

\title{
Stigmata of recent haemorrhage in diagnosis and prognosis of upper gastrointestinal bleeding
}

\author{
D N FOSTER, K J A MILOSZEWSKI, M S LOSOWSKY
}

British Medical fournal, 1978, 1, 1173-1177

\section{Summary and conclusions}

In 277 consecutive episodes of suspected upper gastrointestinal bleeding, lesions bearing stigmata of recent haemorrhage (stigmata) were found by endoscopy in $110(47 \%)$ out of 233 patients who were judged to have bled; $78(33 \%)$ had lesions without stigmata, and in 45 $(19 \%)$ no lesion was seen. Results in 176 entirely unselected admissions for upper gastrointestinal bleeding were similar.

Forty-eight chronic duodenal and 41 chronic gastric ulcers were identified by endoscopy. Stigmata were found in $27(56 \%)$ and $33(80 \%)$ of these cases respectively. Sixteen patients had multiple lesions, and in $12(75 \%)$ the presence of stigmata permitted diagnosis of the source of the haemorrhage. Stigmata were more likely to be seen in cases of duodenal ulcer, Mallory-Weiss lesions, and oesophageal varices when endoscopy was performed within 12 hours of bleeding, but were as common in cases of gastric ulcer after longer intervals.

In the absence of stigmata one out of 21 patients with duodenal ulcer had further haemorrhage and one other needed emergency surgery; no patient with gastric ulcer

University Department of Medicine, St James's Hospital, Leeds LS9 7TF

D N FOSTER, MB, MRCP, senior registrar (now consultant physician, Birch Hill Hospital, Rochdale, Lancs)

K J A MILOSZEWSKI, BSC, MRCP, senior lecturer and honorary consultant physician

M S LOSOWSKY, MD, FRCP, professor of medicine had further haemorrhage or needed emergency surgery. In contrast, when stigmata were present 15 of the 27 patients with duodenal ulcer $(56 \%)$ had further haemorrhage and $17(63 \%)$ needed emergency surgery; of the 33 patients with gastric ulcer, $10(30 \%)$ had further haemorrhage and $15(45 \%)$ required emergency surgery. Superficial mucosal lesions may have been the source of haemorrhage when an ulcer unmarked by stigmata was seen at endoscopy. Stigmata were superior to any other single factor or combination of factors in predicting rebleeding and the need for emergency surgery.

\section{Introduction}

Endoscopy is considered to be the best means of identifying the source of bleeding in upper gastrointestinal haemorrhage. ${ }^{1-8}$ Evaluation of reported diagnostic accuracy is difficult since criteria for accepting a lesion as the source of bleeding are often not stated ${ }^{7-13}$ and the selection of patients is often not explicit. ${ }^{1012}$ The usefulness of emergency endoscopy is difficult to assess since most reports document the interval before endoscopy from the time of admission ${ }^{14-17}$ rather than from the time of the first symptoms of bleeding. Patients who rebleed after admission have a significantly higher mortality ${ }^{18-23}$; many patients with peptic ulcer rebleed, ${ }^{18}{ }^{21-23}$ and there is no satisfactory way of identifying those at risk. We studied patients with special reference to these features in diagnosis, prognosis, and management.

\section{Patients and methods}

A consecutive series of 277 episodes of suspected upper gastrointestinal bleeding was managed by our unit during 38 months; 176 were unselected emergency admissions, and 101 were selected (from 